\title{
A formulação das doutrinas do Estado e do Direito elaboradas pelo jovem Schopenhauer: extensão, limites e mudanças em relação à publicação de sua obra magna
}

\author{
The formulation of the doctrines of the State and of the Entitlement \\ developed by young Schopenhauer: extension, limits and changes \\ regarding to the publication of his masterwork
}

\author{
Felipe dos Santos Durante \\ Doutorando em Filosofia pela UNICAMP/Bolsista da FAPESP
}

E-mail:xfelipedurantex@gmail.com

\begin{abstract}
Resumo: Este trabalho tem por objetivo, a partir da leitura e análise dos manuscritos de juventude (Der handschriftliche Nachlass - Frühe Manuskripte) datados de 1804-1818, reunir os fragmentos que serviram como base constituinte das doutrinas do direito e do Estado formuladas pelo filósofo da vontade, Arthur Schopenhauer, com vistas a avaliar a extensão, os limites, e as mudanças das enunciações do jovem autor efetuadas na edição de 1844 de sua obra magna, $O$ mundo como vontade e como representação. Este esforço compreende três etapas: (i) exegese dos manuscritos de juventude, a fim de selecionar os fragmentos relacionados à temática, (ii) exegese do livro IV de $M V R$, principalmente do $\S 62$ e do capítulo 47 do segundo tomo da obra, nos quais as referidas doutrinas são formuladas; (iii) avaliar a inserção, a extensão e o impacto dos escritos do jovem Schopenhauer na edição de 1844 de $M V R$.
\end{abstract}

Palavras-chave: Direito; Estado; Manuscritos de Juventude.

\begin{abstract}
From the reading and analysis of Schopenhauer's early manuscripts (1804-1818 Der handschriftliche Nachlass - Frühe Manuskripte), this article aims to show the fragments that were the basis of the doctrines of right and the State in order to evaluate the extent, limits, and changes of the young author in his main work, The World as Will and Representation of 1844. This effort comprises three stages: (i) exegesis of the Schopenhauer's early manuscripts, (ii) exegesis of the Book IV of $W W V$, especially the $\S 62$ and Chapter 47 of the second volume of the work, (iii) evaluate the insertion, the extent and impact of the writings of the young Schopenhauer in the 1844 edition of $W W V$. When developing the foregoing stages, it is expected to explain the importance and impact of young Schopenhauer's notes in his principal work.
\end{abstract}

Keywords: Right; State; Early Manuscripts. 
Em geral, quando o nome de Arthur Schopenhauer ${ }^{1}$ é mencionado no Brasil, são evocadas diferentes lembranças sobre o autor, de acordo com cada interlocutor: há quem se recorde do "filósofo do pessimismo"; existem aqueles que são remetidos ao "pensador do sistema único, do sistema expresso em $O$ mundo como vontade e como representação"; e há ainda quem o reconheça como "aquele autor de obras mais popularescas e vendáveis, como Aforismos para sabedoria de vida, A arte de ter razão, A arte de ser feliz, e toda sorte de artes que possam ser atrativas comercialmente para o ramo editorial". Longe dos escritos éditos do autor, que se caracterizam pela exposição mais acabada de seu sistema filosófico, podemos encontrar as anotações fragmentadas de um jovem inquieto e amargurado que admirava seu pai e era frustrado por não ter o amor de sua mãe da forma como gostaria que esse o fosse. Essas anotações já continham em gérmen toda a essência do sistema filosófico da vontade. Nesses escritos, principalmente em seus diários de anotações que datam dos anos de 1804 a 1818, podemos verificar, como escreve Roberto Aramayo, a "lenta gestação da obra schopenhaueriana" ${ }^{\text {. }}$. Além do processo de composição do filósofo, os manuscritos que chegaram até nós postumamente possuem passagens preciosas e que muitas vezes complementam as lacunas argumentativas e expositivas deixadas pelo filósofo, tornando-se uma fonte extremamente rica para o melhor entendimento de sua filosofia. A análise histórico-filológica do espólio de juventude do autor representa uma complementação consistente no que se refere à obra publicada, uma vez que permite contemplar dois aspectos de sua produção intelectual, que são enunciados por Safranski da seguinte forma:

A obra final pretendia resolver problemas; em troca, o manuscrito permite entrever o sentido existencial contido nesses mesmos problemas. Foram os cadernos de anotações que apresentaram as

\footnotetext{
${ }^{1}$ Adotou-se a edição das obras completas em alemão organizadas por Paul Deussen: SCHOPENHAUER, A. Arthur Schopenhauers sämtliche Werke; Hrsg. Von Paul Deussen. Munique: R. Piper, 1911-1942. A tradução adotada de Die Welt als Wille und Vorstellung para uma leitura cotejada com a obra em idioma alemão foi feita por Jair Lopes Barboza: O mundo como vontade e como representação, Tomo I. São Paulo: Editora UNESP, 2005 (doravante abreviado como MVR, seguido da indicação de parágrafo e página, e do tomo e da paginação em referência à edição alemã. Após cada citação, serão apresentados em nota de rodapé os excertos utilizados em seu idioma original).

2 ARAMAYO, R. Los Bocetos del Sistema Filosófico Schopenhaueriano. In: SCHOPENHAUER, A. Escritos Inéditos de Juventud 1808-1818 Sentencias y Aforismos II; seleção, introdução e tradução de Roberto R. Aramayo. Valencia: Pre-Textos, 1999, p.10. 
questões, enraizadas no corpo e na vida humana, a que a obra se destinou a responder ${ }^{3}$.

Recorrer aos Nachlass representa um ganho na medida em que (i) é possível entrar em contato com exemplos diversos dos que foram empregados na obra publicada - amiúde mais explícitos, simples, e intuitivos; (ii) é possível entrar em contato com diferentes formulações que intentam explicar um mesmo evento, o que expõe a forma como o autor abordou o problema e lança uma luz diferente sobre o objeto analisado; (iii) é um trabalho ainda pouco explorado pelas pesquisas sobre Schopenhauer no Brasil.

O trabalho de análise dos manuscritos de juventude nos revela que tanto a doutrina do direito, quanto a doutrina do Estado - e as temáticas a elas relacionadas e implicadas - foram objeto de reflexão do jovem pensador dos anos de 1810 até 1818. Ao menos onze fragmentos que expressam esse momento de reflexão do filósofo devem ser considerados ${ }^{4}$, em especial o fragmento 286, datado de 1814 .

A argumentação para a doutrina do direito de Schopenhauer - termo emprestado de Kant que designa tanto o direito natural quanto o direito positivo ${ }^{5}$ - pode ser dividida em, pelo menos - das várias divisões exequíveis -, seis momentos da argumentação: (i) a manifestação do conflito interno da vontade no âmbito fenomênico, responsável pela guerra de todos contra todos, ou seja, a caracterização do egoísmo (Egoismus); (ii) como esse conflito, resultado da afirmação da própria vontade de viver, é a origem da injustiça (Unrecht); (iii) a caracterização, pela via negativa, da justiça; (iv) a definição, a partir dos conceitos anteriores, do direito natural, que para Schopenhauer é um direito moral; (v) a

\footnotetext{
${ }^{3}$ SAFRANSKI, R. Schopenhauer e os anos mais selvagens da filosofia: uma biografia. Trad. Willian Lagos. São Paulo: Geração Editorial, 2011, p. 361.

${ }^{4}$ São eles: Fragmento 25 - Folhas Iniciais 1-8 1810-1811, Fragmento 27 - Folhas Iniciais 1-8 1810-1811, Fragmento 64 - Berlin 1812 - Folha D, Fragmento 255 - Dresden 1814 - Folha M.M, Fragmento 286 Dresden 1814 -Folha Q.Q - R.R., Fragmento 535 - Dresden 1816 - Folha i.i.i.i., Fragmento 536 v Dresden 1816 - Folha i.i.i.i., Fragmento 537 - Dresden 1816 - Folha i.i.i.i., Fragmento 567 - Dresden 1816 - Folha p.p.p.p. - q.q.q.q., Fragmento 693 - Dresden 1817 - Folha 17, Fragmento 714 - Dresden 1818 - Folha 19. Para sua leitura e análise foram utilizadas as edições alemã e inglesa: Der handschriftliche Nachlaß. ed. Arthur Hübscher Munique, Deutsche Taschenbuch Verlag, 1985, 5 vols. e Manuscript Remains in Four Volumes; Editado por Arthur Hübscher, traduzido por E..F.J. Payne. Oxford : Berg, 1988-1990. Doravante abreviado como $M P$, seguido de tomo, fragmento, ano, paginação original, paginação da obra em inglês, e trecho citado em alemão. As traduções são de minha autoria a partir do texto alemão.

5 " $O$ termo doutrina do direito (usado por Kant) é excessivamente genérico, ele designa o gênero que compreende as duas espécies de doutrinas do direito, o natural e o positivo". MP, I, Dresden 1816 - Folha p.p.p.p. - q.q.q.q., Fragmento 567, P. 383, P. 423. No original alemão: ,[...] das Wort Rechtslehre (das Kant gebraucht) ist zu allgemein, es bezeichnet das genus, das die 2 Species natürliche und positive Rechtslehre begreift.“
} 
origem e a finalidade do Estado (Staat); (vi) e como o direito moral é utilizado de parâmetro pela política para a instituição do direito positivo, fundamentando o direito penal (Strafrecht).

O primeiro aspecto que seria interessante notar é o processo de desenvolvimento e aperfeiçoamento do conceito de egoísmo. A identificação entre o corpo e a vontade já era operada pelo jovem filósofo nas suas anotações mais antigas: "A vontade é o conhecimento a priori do corpo; e o corpo é o conhecimento a posteriori da vontade" No fragmento 286, datado de 1814, o qual parece ser um dos primeiros rascunhos do que viria a constituir a redação final do $\S 62$ de $M V R$, o jovem Schopenhauer desenvolve a tese de que somos seres físicos (physisches Wesen): somos um corpo (Leib), que é objetidade (Objektität) da vontade, que se afirma no tempo, e que quer se preservar e continuar a existir da melhor forma possível. Schopenhauer denomina esse processo de interesse físico (physisches Interesse): a vontade de autoafirmar-se no mundo fenomênico, de ser e de continuar sendo, nas melhores condições possíveis. Isso implica, por um lado, invadir a esfera de afirmação da vontade alheia, e, por outro, o enfrentamento de toda negação de vontade proveniente do exterior, i.e., o enfrentamento da negação do meu próprio corpo e da afirmação das outras vontades sobre a minha. Isso significa, segundo Schopenhauer, ser moralmente interessado em não sofrer injustiça. E injustiça, aqui, já é entendida como invasão do corpo. Contudo, a noção de interesse físico deixa de ser utilizada pelo filósofo, e nos fragmentos posteriores apenas o termo egoísmo é empregado.

Nos textos éditos de Schopenhauer, o egoísmo é tido como a motivação fundamental entre os seres dotados de entendimento - os animais e os homens - porque ele pode ser entendido como um ímpeto para existência - uma existência desejada incondicionalmente - e para o bem-estar, o que o identifica com a afirmação da vontade de vida e leva os homens a afirmarem a própria vontade até a invasão da esfera de afirmação de outrem. Em termos gerais, apesar da variação da palavra com a qual se designa o conceito, o seu conteúdo já estava bem delimitado nas anotações analisadas.

A injustiça, como mencionado acima, já é concebida pelo jovem pensador como a invasão da esfera de afirmação da vontade, i.e., como a afirmação da vontade que vai

\footnotetext{
${ }^{6}$ MP, I, Dresden 1814 - Folha M.M - Fragmento 255, P. 153, P.167. No original alemão: „Der Wille ist die Erkenntniß a priori des Leibes. Und der Leib ist die Erkenntniß a posteriori des Willens“. 
até outro corpo e o nega ${ }^{7}$. No fragmento 286 (1814), Schopenhauer admite a injustiça como uma invasão realizada por meio do canibalismo, do homicídio ou pela utilização das forças alheias pertencentes a uma vontade objetivada em um corpo, por outro corpo. Desse último caso são derivadas a injustiça que configura a escravidão, embora Schopenhauer já vislumbre escusas para justificá-la - as quais enuncia de forma mais demorada apenas no $\$ 125$ de $P P(1851)$-, e a injustiça que se refere ao dano à propriedade.

No fragmento 714, datado de 1818, aparecem pela primeira vez as formas pelas quais Schopenhauer considera o exercício da injustiça: pela astúcia (List) e pela violência (Gewalt), com praticamente o mesmo teor apresentado na redação final de MVR. A única diferença que parece ser substancial é a de que, nos manuscritos, Schopenhauer considera toda mentira como injustiça ${ }^{8}$, posição que se altera, como se sabe, em seus textos éditos ${ }^{9}$.

Em seus textos publicados, Schopenhauer escreve que a injustiça pode ocorrer por (i) ferimento / dano / lesão (Verletzung), (ii) por destruição do corpo de outrem ou (iii) quando ocorre a imposição de uma vontade particular a uma vontade alheia - que é negada e passa, então, a servir à vontade impositiva ${ }^{10}$, e pode afetar a pessoa (Person), a liberdade (Freiheit), a propriedade (Eigentum), e a honra (Ehre) ${ }^{11}$.

Schopenhauer caracteriza cinco graus em que a injustiça se manifesta, estabelecendo como critério para tal classificação o grau de objetivação da vontade. Em suas preleções sobre a ética, o filósofo da vontade expõe a temática de forma mais

\footnotetext{
${ }^{7}$ Cf. $M P$, I, Dresden 1814 - Folha Q.Q - R.R. - Fragmento 286, P. 174-176, P.189-192 (que parece constituir o primeiro rascunho), e $M P, I$, Dresden 1817 - Folha 17 - Fragmento 693, P.482-483, P.534 (fragmento com o texto mais próximo da redação final).

${ }^{8}$ Cf. $M P, I$, Dresden 1818 - Folha 19 - Fragmento 714, P.490, P.543.

${ }^{9}$ Aqui remeto ao leitor interessado na questão da mentira o texto do professor Oswaldo Giacoia que articula a exposição da problemática do direito à mentira com o contexto histórico-filosófico do iluminismo e sua recepção: Cf. GIACOIA, O. A Mentira e as Luzes: Aspectos da Querela a Respeito de um Presumível Direito de Mentir. In: PUENTE, F. R. (org.). Os Filósofos e a Mentira; Belo Horizonte: Editora UFMG; Departamento de Filosofia - FAFICH/UFMG, 2002.

${ }^{10}$ Cf. $M V R, \S 62$, p. 429, I 394.

${ }^{11}$ Aqui temos uma pequena discrepância entre formulações: somente no escrito SFM, do ano de 1840 , Schopenhauer inclui a invasão dos limites da afirmação da vontade que correspondem à liberdade como uma das possibilidades de ocorrência da injustiça. (Cf. SFM, §17, P.150-151, III 689-690). Na formulação dos $P P$, datada do ano de 1851, a liberdade não é mencionada como uma categoria passível de ser afetada de forma a ser configurada uma injustiça. (Cf. PP. Capítulo 9 - Sobre a doutrina do direito e a política, $\S 121$, P. 241, V 264). Em última instância, o ataque à pessoa, à liberdade, à propriedade e à honra parecem se configurar como ataques à esfera de afirmação da vontade do indivíduo. Como parece estranho, a partir dessa perspectiva de interpretação do conceito, desconsiderar um elemento tão importante como a liberdade, decidiu-se por manter a formulação feita em SFM por considerá-la a mais completa, embora nesse artigo nos atenhamos apenas ao $M V R$.
} 
flexível. Ele reconhece os mesmos cinco graus de injustiça, mas admite duas pequenas modificações: (i) que a ação possa ser de natureza mista e corresponder a mais de um dos graus ao mesmo tempo ${ }^{12}$, e (ii) uma rubrica (Rubrik) especial de injustiça, que é derivada do não cumprimento das obrigações relativas às relações sexuais (Sexualverhältni $\beta)$ - que consistiria um sexto tipo de injustiça ${ }^{13}$.

Além do canibalismo, do homicídio e da sobreposição de vontades (que no fragmento mencionado configuram a injustiça por escravidão e a injustiça relativa ao dano à propriedade), a mera lesão do corpo de outrem é considerada como uma forma de praticar injustiça e o ataque à propriedade se torna o quinto grau de injustiça, ganhando consideração à parte na formulação do autor ${ }^{14}$.

Contudo, o que é mais marcante nos manuscritos de juventude é o fato de Schopenhauer assinalar por diversas vezes que os homens temem a possibilidade do sofrer injustiça, não propriamente a sua prática - que até é prazerosa. ${ }^{15}$ Por isso ela é denunciada e condenada. Quê seria a justiça e as formas de evitá-la também são temáticas abordadas pelo jovem Schopenhauer e fazem parte do desenvolvimento argumentativo das doutrinas do direito e do Estado em suas anotações.

O conceito de justiça é definido em todos os escritos de Schopenhauer como um conceito moral originado da negação da injustiça, i.e., que a manifestação individual da vontade não vá para além de seu próprio fenômeno, que a esfera de afirmação do outro não seja invadida. ${ }^{16}$ Por ser definida a partir da negação da injustiça, pode-se afirmar que essa é a condição de existência da justiça, que é toda ação praticada que não cause dano ao corpo de outrem, que não afete a esfera de afirmação da vontade do indivíduo em sua pessoa, em sua liberdade, em sua propriedade, e em sua honra.

A vontade que intenta negar a minha vontade pode ser tratada, segundo Schopenhauer, como uma força natural operando cegamente e que deve ser evitada de toda forma. ${ }^{17}$ Ao evitar a sobreposição da minha vontade pela de outrem, permaneço sem incorrer em injustiça, afirmando o meu corpo, minha vontade, sem negar a de

\footnotetext{
${ }^{12}$ Cf. MP, Metafísica dos Costumes, P.90, P.150.

${ }^{13}$ Cf. MP, Metafísica dos Costumes, P.90, P.150.

${ }^{14}$ Aqui é importante mencionar que os apontamentos mais essenciais relativos ao direito de propriedade, como sua identificação com a vontade do indivíduo através do trabalho elaborador, sua exterioridade ao Estado, podem ser encontrados nos fragmentos 286 (1814), 563(1816), 672 (1816), e 693 (1817).

${ }^{15}$ Cf. Fragmentos 64 (1812), 286 (1814), 535 (1816), 537 (1816), 693 (1817), e 714 (1818).

${ }_{17}^{16}$ Essa definição pode ser encontrada, por exemplo, nos fragmentos 535 (1816) e 693 (1817).

${ }^{17}$ Cf. MP, I, Dresden 1814 - Folha Q.Q - R.R. - Fragmento 286, P.175, P.191. Nesse ponto fica novamente clara o acento que Schopenhauer dá ao horror em sofrer injustiça.
} 
outrem. E se for necessário compelir a vontade alheia que intenta infligir-me algum tipo de injustiça, posso compeli-la a desistir, em outras palavras, possuo um direito de coerção:

Se eu agora afastar de mim uma tal penetrante negação da minha vontade (em seu fenômeno, [i.e.], meu corpo), então eu apenas nego essa negação, e isso ainda é apenas a afirmação do meu próprio corpo (i.e., vontade), não uma negação de uma vontade alheia, mas sim apenas a sua negação da minha [vontade]: consequentemente isso não é injustiça: tal afastamento é assim um direito, o qual poderia aparecer como se quisesse, por exemplo, a morte de um corpo alheio, quando não existiu outra [maneira] de deter uma ameaça a minha vontade ${ }^{18}$.

Enquanto ser físico sou um corpo, e esse corpo é uma objetidade da vontade que se afirma no tempo; e isso significa dizer que busco a manutenção do meu próprio corpo, a continuidade da existência, nas melhores condições possíveis. Oposto a esse meu objetivo está toda vontade que se coloque em enfrentamento com a minha própria vontade, toda negação do meu corpo que seja oriunda do exterior, que seja oriunda do ultrapassamento das fronteiras de afirmação de vontades estabelecidas. Enquanto ser físico existe o meu interesse de não sofrer injustiça e, exatamente por essa razão, devo negar a negação do meu corpo, num processo no qual permaneço me afirmando sem necessariamente negar o corpo de outrem. O meu interesse físico, i.e., o meu egoísmo, estará de acordo com a minha moral, e nisso, segundo o jovem Schopenhauer, consiste o direito. O direito, e melhor dizendo, o direito natural, é definido nesse contexto da seguinte forma:

$O$ direito é assim a compatibilidade do interesse físico com a moralidade, na medida em que o direito vai apenas até a afirmação da própria vontade. Isso é propriamente o direito, e esse conceito pertence à Ética, o qual poderia conservar o nome de direito natural, e

\footnotetext{
${ }^{18}$ MP, I, MP, I, Dresden 1814 - Folha Q.Q - R.R. - Fragmento 286, P. 175, P. 190-191. No original alemão: "Wenn ich nun eine solche auf mich eindringende Verneinung meines Willens (in seiner Erscheinung, meinem Leibe) abwehre; so verneine ich nur jene Verneinung, und dies ist immer nur noch die Bejahung meines eignen Leibes (d.i. Willens), nicht aber Verneinung eines fremden Willens, sondern nur seiner Verneinung des meinen: folglich ist dies nicht Unrecht: ein solches Abwehren ist also Recht, es möge erscheinen wie es wolle, z.B. als Tödtung eines fremden Leibes, wenn dieser nicht anders von der Beeinträchtigung des meinem abzuhalten war“".
} 
que conserva a distinção com o [direito] positivo. Então deduzimos até aqui o direito natural ${ }^{19}$.

Apenas no fragmento 567 (1816) o jovem Schopenhauer identifica o termo direito natural com o termo direito moral, apesar de anteriormente ter concebido injustiça e justiça como conceitos morais. Essa identificação consiste no fato de que, por serem determinações morais, os direitos derivados dos conceitos de injusto e de justo podem ser denominados naturais, no sentido de que não estão definidos por convenções humanas nem são instituídos pelo Estado, mas existem de maneira inata - valem por si e em si -, e são universais e imutáveis - pois valem para todos os indivíduos, em qualquer localidade, e em qualquer época. Como são conceitos morais e a base do direito natural, Schopenhauer pôde concluir que o direito natural é um direito moral tal como aparece na formulação de $M V R$ :

Essa significação puramente moral é a única que a justiça e a injustiça têm para os homens enquanto homens, não como cidadãos do Estado, e que, portanto, subsistiria inclusive no estado de natureza, sem lei positiva. Significação que constitui a fundação e o conteúdo de tudo aquilo que, por esse motivo, se denominou Direito Natural, que se poderia melhor denominar direito moral, pois sua validade não se estende ao sofrimento, à realidade externa, mas só ao ato e ao autoconhecimento oriundo desse ato da vontade individual, autoconhecimento que se chama consciência moral $^{20}$.

A moral teria como objetivo que eu não fizesse injustiça, mas, como visto, o anelo maior é não sofrê-la. O meio racional para obtenção desse fim é o Estado. O Estado surge do meu interesse em não sofrer injustiça, não de que ela não seja praticada. Na medida em que os homens são corpos, seres físicos, e há um interesse físico de cada

\footnotetext{
${ }^{19}$ MP, I, Dresden 1814 - Folha Q.Q - R.R. - Fragmento 286, P. 176, P.191-192. No original alemão: „Das Recht ist also die Kompatibilität des physischen Interesses, sofern es nur bis zur Bejahung des eignen Leibes geht, mit dem moralischen. Dies ist das eigentlich Recht, dessen Begriff zur Et[h]ik gehört, und das den Namen des Naturrechts, den es zur Unterscheidung vom positivem erhalten hat, behalten mag. Wir haben also bis hieher das Naturrecht deducirt".

${ }^{20} M V R, \S 62$, P.437, I 403. No original: „Diese rein moralische Bedeutung ist die einzige, welche Recht und Unrecht für den Menschen als Menschen, nicht als Staatsbürger haben, die folglich auch im Naturzustande, ohne alles positive Gesetz, bliebe und welche die Grundlage und den Gehalt alles dessen ausmacht, was man deshalb Naturrecht genannt hat, besser aber moralisches Recht hieße, da seine Gültigkeit nicht auf das Leiden, auf die äußere Wirklichkeit, sondern nur auf das Thun und die aus diesem dem Menschen erwachsende Selbsterkenntniß seines individuellen Willens, welche Gewissen heißt, $[\ldots]$ “. Nota-se neste excerto a primeira inversão na ordem dos termos: injustiça e justiça, empregados até então sempre nesta ordem, para justiça e injustiça.
} 
um em não sofrer injustiça, cria-se o acordo para que ninguém faça injustiça, já que, assim, ninguém sofreria injustiça. O Estado é concebido, dessa forma, como prevenção, mais precisamente como prevenção ao sofrimento de injustiça. Dessa forma, no fragmento 286 (1814), Schopenhauer define o Estado como "a comunidade de pessoas que não desejam sofrer qualquer injustiça" ${ }^{\text {21 }}$. No fragmento 537 (1816), corroborando o fragmento anterior, o pacto social que dá origem ao Estado é concebido como renúncia ao fazer injustiça. Desta forma, na argumentação levada a cabo nos manuscritos de juventude, em comparação com os textos éditos, a separação entre Estado e moral parece se constituir de modo mais explícito, embora fique aparente que os indivíduos realmente renunciem à prática da injustiça ao invés de instituir um dispositivo coercitivo que, através de contramotivos, desestimule as ações injustas.

O Estado surge por um acordo, por um pacto, e utiliza-se do inverso ${ }^{22}$ da doutrina pura do direito para garantir que seus protegidos não sofram injustiça. Segundo o fragmento 536 (1816), o principal de uma exposição da doutrina do direito é mostrar que o direito positivo é o emprego e uso do direito natural em seu reverso. Em uma nota de um fragmento posterior, a saber, 567, datado do mesmo ano, Schopenhauer elenca quais ele considera serem os pontos principais de que todas as doutrinas do direito se ocuparam:

Os pontos principais do direito natural são: 1) a definição do conceito de justiça / direito, e a demonstração de sua origem e sua relação com a moral e o direito natural; 2) A constituição e finalidade do Estado; 3) A dedução do direito de propriedade - o conteúdo restante de uma doutrina do direito natural é apenas a aplicação dos seus princípios, a determinação do que é possível nas relações da vida, que assim são reunidos sob certos conceitos gerais no direito, isto é, como os seres humanos agem em todos os lugares para que nenhum sofra injustiça. Todas as doutrinas do direito concordam nesses pontos particulares,

\footnotetext{
${ }^{21} M P$, I, Dresden 1814 - Folha Q.Q - R.R. - Fragmento 286, P. 176, P.192. No original alemão: „Er ist also eine Vereinigung von Menschen die Kein Unrecht leiden wollen“.

${ }^{22}$ Nos manuscritos de juventude Schopenhauer utiliza tanto a palavra alemã umgekehrte, quanto a palavra Kehrseite para se referir a dinâmica que consiste no fato da política utilizar-se do reverso / inverso / avesso do direito natural para estabelecer o direito positivo. E o que significa empregar o direito natural em seu reverso? Significa que a doutrina pura do direito tem como base o dado a partir da moral, do caráter, do âmbito interno da experiência, enquanto que a teoria do Estado considera o que é dado a partir da motivação. Ou seja, estabelecidos o injusto e o justo como padrão objetivo de medida (quais sejam: o injusto se configura pela invasão da esfera de afirmação da vontade no corpo alheio e que o justo é a negação do conceito de injustiça), invertem-se a perspectiva e a ordem dos valores: a legislação vigorará de acordo com o limite do justo estabelecido, que não pode ser transcendido no âmbito da experiência externa.
} 
assim, elas também discursam de forma diferente sobre aqueles três pontos principais, e assim em seus princípios ${ }^{23}$.

O Estado é concebido, assim, como o egoísmo contra as consequências desvantajosas do egoísmo (ou, em termos mais simplórios consoantes com as primeiras formulações do jovem filósofo, do interesse físico pela preservação e prevenção), operando a inversão do conceito de justiça moral para o de justiça legal: o ponto de partida é alterado do lado ativo (agir), para o lado passivo (sofrer injustiça). No fragmento 535 (1816), já é possível notar o significado latente de dois tipos de egoísmos nessa questão, a saber, egoísmo coletivo ou esclarecido e o egoísmo individual:

Aqueles que acham que o Estado é uma instituição moral; eles pensam que o Estado é orientado contra o egoísmo mesmo: mas, pelo contrário, ele é orientado contra as consequências do egoísmo, a saber, contra as consequências do egoísmo alheio, contra as quais o próprio se volta: assim, o Estado se originou inteiramente do egoísmo e ele está aí para servi-lo com a razão, conforme exposto de maneira excelente por Hobbes ${ }^{24}$.

Assim, tem-se constituído, já nos manuscritos de juventude, aspectos da filosofia schopenhaueriana que permeiam toda a doutrina do direito e do Estado conforme sua redação mais acabada. A separação entre moral e Estado é apenas um dos aspectos engendrados pela dicotomia vontade e representação: a moral é eterna, perene, constituí a unidade, tem como escopo de investigação a disposição em cometer injustiça; o Estado, por sua vez, é temporal, aparência, regido pelos princípios de individuação e de razão e, assim, pelo conflito da multiplicidade, possuindo como escopo de investigação

\footnotetext{
${ }^{23}$ MP, I, Dresden 1816 - Folha p.p.p.p. - q.q.q.q. - Fragmento 567, P. 382, P. 422, nota de rodapé. No original alemão: „Die Hauptpunkte des Naturrechts sind 1) die Definition des Begriffs Recht, und Nachweisung seines Ursprungs und seines Verhältnisses zur Moral und zum Naturrecht. 2) Die Entstehung und der Zweck des Staats. 3) Die Ableitung des Eigenthumsrechts. - Der übrige Inhalt einer Lehre des Naturrechts ist bloß die Anwendung jener Principien, die Bestimmung, was in den möglichen Verhältnissen des Lebens, die deshalb unter gewisse allgemeine Begriffe vereinigt sind Recht, ist, d.h wie Menschen überall zu handeln haben damit keiner Unrecht leide. Alle Rechtslehren stimmen in diesem mehr Besonderen überein, so verschieden sie auch von jenen 3 Hauptpunkten reden, also in den Principien".

${ }^{24} M P$, I, Dresden 1816 - Folha i.i.i.i. - Fragmento 535, P. 358, P. 395. No original alemão: „Die, welche meinen, er [Staat] sei eine moralische Anstalt; denken er sei gegen den Egoismus selbst gerichtet: er ist aber vielmehr gegen die Folgen des Egoismus gerichtet, nämlich gegen die Folgen des fremden Egoismus, gegen die der eig[e]ne sich auflehnt: er ist also ganz aus dem Egoismus entstanden und ist da um demselben zu dienen mit Vernunft, wie Hobbes vortrefflich auseinandersetzt.“
} 
$\mathrm{o}$ ato, o feito ${ }^{25}$. Apenas o ato pode ser punido pelo Estado. Da mesma forma como o historiador é um profeta às avessas, o legislador seria, assim, um moralista às avessas. E que conste aqui: para o jovem de 22 anos, o político seria um ético às avessas, mas esse exemplo foi suprimido de todas as suas publicações ${ }^{26}$, talvez pelas ambiguidades que sua interpretação poderia gerar.

Por fim, resta a consideração de que a essência do direito penal, tal como formulada na obra do filósofo da vontade, não encontrou grandes alterações dos fragmentos de juventude para a versão mais acabada de seus escritos. A punição (Strafe) é orientada em essência para o futuro (Zukunft), não para o passado (Vergangenheit), fator que a difere da vingança (Rache $)^{27}$.

A partir do exposto, tentou-se mostrar que, apesar do aspecto fragmentário, da não sistematização precisa, e, portanto, da não complexidade da redação final da obra publicada, o aporte teórico, conceitual e as principais linhas argumentativas que se referem às doutrinas do Estado e do direito, já se encontravam de forma latente ou em desenvolvimento nos fragmentos de juventude de Arthur Schopenhauer. Paralelamente, pôde-se observar, também nessa análise, o processo de refinamento conceitual e de redação que constam na terceira edição da obra magna do filósofo.

\section{Referências}

ARAMAYO, R. Los Bocetos del Sistema Filosófico Schopenhaueriano. In: SCHOPENHAUER, A. Escritos Inéditos de Juventud 1808-1818, Sentencias y Aforismos II. Seleção, introdução e tradução de Roberto R. Aramayo. Valencia: Pre-Textos, 1999.

. Para Leer a Schopenhauer. Madri: Alianza Editorial S. A, 2001.

CARTWRIGHT, D. Historical Dictionary of Schopenhauer's Philosophy. In: Historical dictionaries of religions, philosophies, and movements, $n^{\circ}$. 55. Oxford: Scarecrow Press, 2005.

\footnotetext{
${ }^{25}$ Cf. MP, I, Folhas Iniciais 1-8 1810-1811 - Fragmento 25, P.16-17, P.16-17.

${ }^{26}$ Cf. $M P$, I, Folhas Iniciais 1-8 1810-1811 - Fragmento 25, P.16-17, P.16-17.

${ }^{27}$ Sobre a punição, a vingança e o direito penal, Cf. os Fragmentos 413 (1815), 568 (1816), 574 (1816), e 620 (1816).
} 
GODART-VAN DER KROON, A. Schopenhauer's Theory of Justice and its Implication to Natural Law. In: Jahrbuch der Schopenhauer-Gesellschaft, 2003, Band 84. Frankfurt am Main: Verlag Köningshausen \& Neuman Würzburg, 2003, p. 121-145.

SAFRANSKI, R. Schopenhauer e os anos mais selvagens da filosofia: uma biografia. Tradução Willian Lagos. São Paulo: Geração Editorial, 2011.

SCHOPENHAUER, A. Arthur Schopenhauers sämtliche Werke. Hrsg. von Paul Deussen. Munique: R. Piper, 1911-1942.

Arthur Schopenhauers handschriftlicher Nachlaß.

Philosophische Vorlesungen - Metaphysik der Sitten. In: SCHOPENHAUER, A. Arthur Schopenhauers sämtliche Werke, vol X; hrsg. Von Paul Deussen. Munique: R. Piper, 1911-1942, p.367-584.

. Der handschriftliche Nachlaß. ed. Arthur Hübscher Munique, Deutsche Taschenbuch Verlag, 1985, 5 vols.

Manuscript Remains in Four Volumes; Editado por Arthur Hübscher, traduzido por E.F.J. Payne. Oxford : Berg, 1988-1990.

Parerga and Paralipomena - Short Philosophical Essays; Translated from German by E.F.J. Payne - volume two. Oxford: Claredon Press, 2000.

. Metafísica de las Costumbres; introdução, tradução e notas de Roberto Rodríguez Aramayo. In: Coleção Clássicos de la Cultura; Madri: Editorial Trotta SA, 2001.

. Sobre o Fundamento da Moral. Tradução Maria Lúcia Mello Oliveira Cacciola. São Paulo: Martins Fontes, 2001.

O Mundo como vontade e como representação. Tomo I. Tradução, apresentação, notas e índices de Jair Barboza. São Paulo: Editora UNESP, 2005.

Los dos Problemas Fundamentales de la Ética. Tradução, introdução e notas Pilar López de Santa María. Madri: Siglo XXI de España Editores, 2007.

Sobre a Filosofia e seu Método. Organização e Tradução Flamarion Caldeira Ramos. São Paulo: Hedra, 2010.

WEISSMANN, K. Vida e Obra de Schopenhauer. Belo Horizonte: Itatiaia, 1980. 
Revista Voluntas: Estudos sobre Schopenhauer - Vol. 3, Números 1 e 2 - $1^{\circ}$ e $2^{\circ}$ semestres de 2012 - ISSN: 21793786 - pp. 143-155.

Aprovado: $21 / 12 / 12$

Approved: $12 / 21 / 12$

A formulação das doutrinas do Estado e do Direito elaboradas pelo jovem Schopenhauer: extensão, limites e mudanças em relação à publicação de sua obra magna 